\section{rev Psi}

Revista de Psicología (UNLP)

https://revistas.unlp.edu.ar/revpsi

\title{
La comunicación performer-público en la performance de la música académica
}

\author{
Matías Germán Tanco ${ }^{1}$ \\ Correspondencia \\ matiastanco@fba.unlp.edu.ar \\ Filiaciones institucionales \\ ${ }^{1}$ Laboratorio para el Estudio de la Experiencia \\ Musical (LEEM), Facultad de Bellas Artes, \\ Universidad Nacional de La Plata (UNLP) \\ (Argentina)
}

\section{Resumen}

Se presenta una investigación empírica sobre la performance musical académica en la interacción performer-público mediante la analogía de la narración musical. La metodología empleada fue de tipo cualitativa. Se realizaron entrevistas a un grupo de músicos intérpretes, con el objetivo de obtener descripciones de la comunicación performer-público. Los resultados permiten cuestionar: (i) la direccionalidad única en el entramado comunicativo desde la composición de la obra hasta la situación de concierto; (ii) el rol del performer como un mediador del mensaje enunciado por el compositor hacia el oyente. En su lugar, la performance entendida como una narración de la obra musical implica la creación de una versión de la partitura que en la interpretación del performer es dependiente de las situaciones contextuales y su percepción del público.

\section{Palabras clave}

música | comunicación | performance | performer | narración

\section{Cómo citar}

Tanco, M. G. (2018). La comunicación performer-público en la performance de la música académica. Revista de Psicología 17(2), 22-44. doi: 10.24215/2422572Xe020

DOI

10.24215/2422572Xe020
Recibido

7 sep. 2018

Aceptado

7 dic. 2018

Publicado

28 dic. 2018

Editor

Nicolás Alessandroni | Facultad de Psicología, Universidad Autónoma de Madrid (España)
ISSN

2422-572X

Licencia

(c) Copyright: Tanco, M. G. Este

trabajo se distribuye bajo una licencia

de Cultura Libre CC-BY 4.0

Entidad editora

RevPsi es una publicación de la

Facultad de Psicología (Universidad

Nacional de La Plata, Argentina)

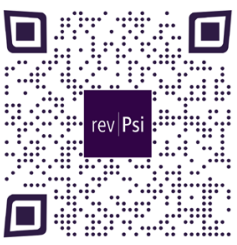

ACCESO ABIERTO DIAMANTE 


\section{A comunicação entre artistas e público na performance da música acadêmica}

\section{Resumo}

A pesquisa empírica sobre a performance musical acadêmica na interação intérpretepúblico é apresentada através da analogia da narração musical. A metodologia utilizada foi de natureza qualitativa. As entrevistas foram realizadas com um grupo de intérpretes de músicos, com o objetivo de obter descrições da comunicação intérprete-pública. Os resultados permitem questionar: (i) a direcionalidade única na estrutura comunicativa desde a composição da obra até a situação do concerto; (ii) o papel do performer como mediador da mensagem enunciada pelo compositor em relação ao ouvinte. Em vez disso, a performance entendida como uma narrativa do trabalho musical envolve a criação de uma versão da partitura que, na interpretação do intérprete, depende de situações contextuais e de sua percepção do público.

\section{Palavras-chave}

música | comunicação | performance | performer | narração

\section{Performer-audience communication in academic music performance}

\section{Abstract}

Empirical research on academic musical performance in the performer-public interaction is presented through the analogy of musical narration. The methodology used was of a qualitative nature. Interviews were conducted with a group of musicians interpreters, with the aim of obtaining descriptions of the performer-public communication. The results allow to question: (i) the unique directionality in the communicative framework from the composition of the work to the concert situation; (ii) the role of the performer as a mediator of the message enunciated by the composer towards the listener. Instead, the performance understood as a narrative of the musical work involves the creation of a version of the score that in the interpretation of the performer is dependent on contextual situations and their perception of the audience.

\section{Keywords}

music | communication | performance | performer | narration 


\section{Aspectos destacados del trabajo}

- La investigación de la comunicación entre performer-público puede ser ampliada desde la perspectiva del performer.

- Los performers perciben al público cuando están realizando una performance académica.

- El performer adopta la posición de público/oyente en la comunicación.

- La co-creación de sentido emerge como una narrativa que no se encuentra en la partitura.

En este artículo abordamos el fenómeno musical desde el intérprete. El término performer será utilizado para nombrar al músico que presenta la obra ante el público. Al hacerlo, decimos que su rol implica la elaboración de sentido de la partitura y su producción sonora. De este modo se inserta en un entramado social diferenciándose del compositor y el oyente/público. El performer realiza actividades que incluyen la lectura, interpretación y práctica de ensayo de una obra, aunque ésta no sea ejecutada ante el público. Nuestro interés particular reside en estudiar la interacción performer-público que se establece en un tiempo y lugar determinados.

Entendiendo al músico como un sujeto social, encaramos una investigación cualitativa, con el interés de acercarnos a las creencias, pensamientos y experiencias de las personas. El estudio consistió en la realización de entrevistas semiestructuradas para obtener descripciones verbales de los músicos. Dichas descripciones fueron analizadas en términos de situaciones análogas a una narración en acto. Se indagaron aspectos relativos a: (i) la relación entre obra-performance y sus similitudes con la de historia-narración; (ii) la interacción entre performer-público en términos de narrador-narratario; $y$ (iii) la actividad creadora del performer como un narrador en la performance. En este escrito nos enfocaremos en la perspectiva del performer para entender a la performance musical como una comunicación.

\section{El modelo tradicional de la música clásica}

La música ha estado presente en la vida humana desde sus inicios. La literatura que la describe es lo suficientemente amplia como para poder enunciar una sola definición. En diferentes lugares, tiempos y situaciones particulares, acompaña la actividad humana en formas más o menos elaboradas y racionalizadas. Así, música puede nombrar una canción de cuna que la madre canta a su bebé o una obra validada y consolidada en la cultura de concierto. En este trabajo abordamos la música académica y su modelo de performance que ha sido denominado como el canon musical universal (Talbot, 2000). 
El modelo tradicional entiende a la música como un arte en sus propios términos, independizada del lenguaje verbal, así como de consideraciones extramusicales (religiosas, sociales o científicas). El concepto de obra surge en la práctica musical clásica a fines del siglo XVIII, enfatizando los aspectos estables y textuales de la música por encima de sus aspectos performáticos. Así, el concepto cumple una función regulativa de la práctica y encuentra su mejor expresión en la noción de werktrue, que significa "ser fiel a la obra" (Goehr, 1992, p. 1).

La creación de la música en este modelo es entonces un asunto de los compositores, mientras que los performers deben seguir las instrucciones escritas en la partitura. Esto supone que la obra está cerrada a la participación de otros agentes, y que la performance musical es una actividad necesaria únicamente para la presentación (o reproducción) de la obra. En la sala de conciertos el público permanece sentado y en silencio, por lo tanto, sus posibilidades de participación se limitan a la contemplación de la obra de arte y su belleza abstracta (Small, 1998). La conservación evita así que se produzcan situaciones nuevas que puedan modificar la obra, garantizando su permanencia inalterable en el tiempo.

Las limitaciones del modelo no solamente condicionan la participación del público: el rol que desempeñan los performers tampoco entra en consideración. La obra como entidad autónoma implica entonces que su significado reside en el objeto y no debe ser alterado. La performance tradicional es un sistema de comunicación de única vía, desde el compositor al oyente individual por medio del performer. El oyente puede contemplar la obra, tratar de entenderla y responder a ésta, pero tanto éste como el performer no tienen nada que contribuir para su significado. Un diagrama de flujo para este modelo de la comunicación:

(...) debería mostrar flechas apuntando desde el compositor a los performers y una multitud de flechas apuntando desde los performers hacia los oyentes que están presentes; pero lo que no mostrarían es alguna apuntando en la dirección inversa, indicando feedback desde los oyentes hacia los performers y seguramente no hacia el compositor (que seguramente esté muerto y entonces no podría recibir algún tipo de feedback). Tampoco las mostraría de oyente a oyente, por lo tanto, no se asume ninguna interacción aquí (Small, 1998, p. 6).

En la actualidad, esta práctica permanece y no ha sido modificada en su esencia. Sin embargo, autores como Small sostienen que la performance musical es mucho más rica como para concentrar su atención en la obra y su efecto en un oyente individual. En cambio, el significado de la música reside en la acción: estos significados no son individuales sino sociales (Small, 1998).

\section{Investigaciones en la psicología de la música}

La comunicación entre el performer y el público es un campo que no ha sido indagado en profundidad por la psicología de la música. Una breve revisión al respecto nos 
permitirá dar cuenta de: (i) cuáles son los temas que se han abordado para dar una explicación a la comunicación; (ii) qué tipo de metodologías fueron aplicadas para su investigación y, finalmente; (iii) qué tipo de estudios resultan necesarios para obtener un mejor panorama del fenómeno en el contexto de la performance académica.

En la mayoría de los casos, los estudios realizados siguieron y aplicaron la explicación del modelo de Shannon y Weaver (1949). Esta teoría matemática de la comunicación da cuenta de un comunicador que utiliza un canal para enviar información a un receptor. Mientras que el canal y el receptor pueden adoptar varias formas, la característica central del modelo es que la información se mueve en una sola dirección (desde el emisor al receptor), y no en el sentido contrario. Varios de los estudios indagaron -de manera parcial- la cadena de comunicación desde el creador de la música (el compositor) hasta el destinatario (el oyente) y sus elementos intermedios (la partitura, el performer, el sonido de la música). Por ejemplo, se estudió la atribución de la emoción en diferentes obras musicales (Hevner, 1936), o en secuencias de tonos (Scherer y Oshinsky, 1977).

Las investigaciones suelen realizarse en situaciones donde no hay interacción real (performers y oyentes en las mismas condiciones de espacio y tiempo). La tarea investigada consiste en escuchar grabaciones de performances que no fueron destinadas a los oyentes particulares. Además, se sabe que los performers tampoco conocían a los destinatarios al momento de grabarlas. De este modo, son estudios que abordan algún tipo de interacción entre las personas y la música grabada, pero no indagan en el vínculo directo entre personas. En su lugar, las grabaciones intentan generar diferentes interpretaciones de una obra de acuerdo a variables aisladas (tempo, timing, articulación, vibrato, timbre, etc.). Guiados por el diseño experimental, los oyentes estiman sus juicios de valor en relación a escalas de puntaje y/o a categorías (triste, alegre, enojado, temeroso, tierno, etc.). Posteriormente las categorías son correspondidas con las intenciones interpretativas propuestas a los performers por los investigadores (Gabrielsson y Juslin, 1996).

Otros estudios fueron más allá de lo estrictamente auditivo, incluyendo performances audiovisuales. Las grabaciones fueron mostradas a los sujetos para indagar la influencia de los estilos de movimiento en la percepción de la música. El diseño experimental en estos casos suele omitir una de las dos condiciones (audio o video) con el objetivo de establecer comparaciones (Davidson, 1993). A pesar de incluir más dimensiones de la experiencia, la mayoría de los estudios considera al público en la medida que sea capaz de responder a la música. Sumado a esto, los objetivos suelen proponer la verificación empírica de teorías o hipótesis previas a la investigación (externas al contexto de la práctica).

Más recientemente, se indagaron nuevas maneras de comunicarse a través de la música que se producen en un contexto específico (DeNora, 2000). En diferentes situaciones de la vida cotidiana, se busca así proveer explicaciones acerca de los procesos musicales, sociales y culturales que subyacen las performances (Miell, MacDonald y Hargreaves, 2005). A diferencia del modelo matemático de la comunicación, los 
nuevos abordajes plantean una comunicación más interactiva y recreativa. Así, se cuestiona la direccionalidad única y se promueve un rol activo del receptor para dar forma al contenido y el significado del mensaje (Cross, 2005, 2010; Juslin, 2005).

Un cuerpo importante de estudios aborda la comunicación performer-oyente desde la perspectiva de éste último. La estrategia más utilizada es la de analizar exhaustivamente grabaciones de performances para dar cuenta de los recursos expresivos que el performer despliega en sus ejecuciones. En estos, casos la perspectiva adoptada es la de tercera persona, y está regida por los criterios del investigador. La experiencia de los músicos profesionales en la actuación en vivo es uno de los temas que no ha sido abordado de forma exhaustiva. En cambio, se ha priorizado la del oyente, y se han favorecido a las metodologías experimentales por sobre las no-experimentales (Geeves, Mcilwain y Sutton, 2014). Abordar la perspectiva del performer permitiría conocer más y mejor ciertos aspectos relevantes de su actividad (interpretativa, creativa y emocional), además de reconocer su importancia en la comunicación.

Algunos estudios permiten acercarse y conocer mejor la perspectiva del intérprete. Van Zijl y Sloboda (2011) indagaron el rol de las emociones sentidas por el performer en la construcción de la performance expresiva. A través de entrevistas en profundidad y registros personales escritos (diarios), los resultados permiten acceder a la información desde las palabras de los músicos. Consideramos que la implementación de metodologías como éstas permite conocer más acerca de los performers. Las entrevistas permiten describir sus acciones sin imponer categorías predeterminadas, y pueden decir mucho acerca sus intenciones artísticas y personales.

Holmes (2011) realizó un estudio con un participante para indagar acerca de la perspectiva del performer en la comunicación. La metodología utilizada permitió obtener abundante información mediante las palabras del músico. Sin embargo, la comunicación se focalizó en los aspectos comunicativos del timbre como un parámetro aislado del fenómeno sonoro en la performance. Geeves et al. (2014) investigaron la experiencia de músicos profesionales incluyendo al público, indagada en términos de una conexión. Los resultados presentaron diferencias en relación a (i) su valoración de la atención y/o sintonía con la audiencia, y (ii) su apertura a la variabilidad.

Un estudio cualitativo piloto con músicos de jazz abordó la relación de reciprocidad entre los músicos y el público, bajo el supuesto que ambos pueden influenciarse mutuamente (Brand, Sloboda, Saul y Hathaway, 2012). Mediante la realización de entrevistas semiestructuradas, el trabajo permite conocer la experiencia desde ambas perspectivas, en igual nivel de importancia. El marco teórico que dio sustento a la investigación estuvo bien enfocado hacia el tema de estudio. Sin embargo, propuso una distinción muy marcada entre la performance académica y jazzística, por lo que sería apropiado un abordaje de ese tipo en las salas de concierto.

\section{La performance como una narración musical}

La relación entre narrativa y música ha sido utilizada como un recurso para referir a 
la música en forma de enunciados lingüísticos. Hacia el año 1990 era frecuente que la literatura musicológica recurriera al establecimiento de relaciones análogas entre la narración y la música. Para Nattiez (1990), -quien inició un acalorado debate sobre la narrativa musical- esta relación era sólo una metáfora que se utilizaba para dar cuenta de la especificidad de la música como despliegue temporal. Podemos considerar las cualidades sintácticas que nos permiten entenderla como un discurso, pero no acceder a la historia. La música como lenguaje presenta limitaciones, por lo que la historia es algo que quedará en la intención del compositor o en una estrategia del oyente.

El panorama de la narrativa musical, lejos de poseer una posición unificada, presenta un desacuerdo general acerca de su naturaleza, propiedades y rango de aplicación (Abbate, 1991; Almén, 2008; Klein, 2013; Maus, 1988, 1991, 2005; Nattiez, 1990, 2013; Shifres, 2007; Tarasti, 1991). El abordaje principal en este campo de teorización y análisis es de tipo lingüístico y estructuralista. Así, se enfoca en la creación de un discurso musical que los compositores organizan como una sintaxis lingüística asociada a la función de un narrador (Almén, 2008).

En la búsqueda de una definición más amplia de la narrativa, encontramos que muchos autores coinciden en que la narración está presente en la vida cotidiana. Estamos rodeados de historias y somos narradores en nuestro día a día. La narración entonces puede dar cuenta de una actividad humana y comunicacional por fuera de la literatura. Podemos estructurar aspectos de la vida y la experiencia debido a que construimos narrativas, organizamos los eventos y sus relaciones a través del tiempo (Fludernik, 2009). De un modo similar la psicología considera que la narración es la que da sentido a la interacción en el mundo social (Bruner, 1990/1991).

La psicología del desarrollo ha estudiado el modo interpersonal de la comunicación entre bebés y adultos, en estrecha vinculación con los modos narrativos que desarrollamos desde el nacimiento. La mirada se dirige hacia instancias anteriores a la adquisición del lenguaje: estructuras afectivas que pueden organizar el tiempo, la comunicación y la performance en un mundo cultural en formación. Imberty (1997) adoptó un enfoque experiencialista que lo llevó a proponer una serie de protocategorías anteriores a la adquisición del lenguaje, entre las que destacamos la protonarrativa. Las cualidades dinámicas que regulan el afecto y la emoción compartidas se constituyen como maneras de estar con el otro, las cuales Imberty asoció a los a vectores dinámicos de la música.

Años más tarde, el modo expresivo culturalmente organizado es la base para definir a la musicalidad comunicativa como un dominio cognitivo específico de la especie (Malloch, 1999; Malloch y Trevarthen, 2009). El rasgo de la musicalidad está presente en una cantidad de comportamientos que caracterizan la cognición humana. En ausencia del lenguaje, el habla de los primeros intercambios adquiere formas de contornos melódicos que son variados en su entonación vocal, en modos que se asemejan a organizaciones morfológicas de la música (Español, 2010). Estudios que analizaron la composicionalidad de las interacciones haciendo uso de las herramientas del análisis musical, identificaron construcciones narrativas a partir de 
un motivo básico que es sujeto a elaboraciones (Martínez, 2007).

Se considera que estas interacciones no son específicamente musicales sino protomusicales, y se entienden como la base para la enculturación y el posterior desarrollo de la musicalidad (en la vida adulta) de modos más formalizados. Tres rasgos que caracterizan a la musicalidad comunicativa son: el pulso, la calidad y las narrativas. Las narrativas aluden al modo en el que los sonidos se organizan en patrones de duración, altura, intensidad y timbre, se despliegan en el tiempo y le dan sentido a la interacción. Atañen, de esta manera, a una configuración co-diseñada de los elementos que la constituyen y a su significado sentido (Español, 2014). La musicalidad comunicativa es atribuida entonces al desarrollo incipiente del lenguaje. Se destacan sus aspectos comunicativos y el lugar de la narrativa para la organización de patrones de significado expresivo, más allá de su contenido musical específico.

En el campo de la música, existen antecedentes que postulan el abordaje de la narración en música desde la performance y la actividad del performer (Abbate, 1991; Meelberg, 2006; Rink, 1994, 1999). Esto nos permite pensar en una narración que no finaliza en la partitura. La comunicación que tiene lugar en la performance puede ser entendida a partir de la identificación del narrador con el rol del performer. Desde este enfoque se ha propuesto que su función es la de "guiar la narración como una experiencia compartida, dando surgimiento a la presencia de un otro" (Shifres, 2007, p. 288).

En este estudio, la narración es entendida en términos de una acción: es el acto real o ficticio que produce ese discurso, el hecho de contar en sí mismo (Genette, 1983/1998). Al hacerlo, rescatamos la actividad basada en la acción de contar historias. Esto plantea una relación entre texto y acto, a la vez que permite incluir prácticas narrativas que no involucran la presencia de textos. El abordaje desde la acción permite situarla en un contexto cultural, tomando algunos aspectos de la narración literaria, pero también en un marco más amplio de la vida. La narración participa así del pensamiento: se construyen mundos posibles a partir de interacciones, transacciones y regulaciones sociales que permiten la interpretación de relatos en el contexto de una cultura (Bruner, 1986/2004). Según el autor, "la narrativa se ocupa de las vicisitudes de la intención (...) la intención es inmediata e intuitivamente reconocible: no parece requerir para su reconocimiento ningún acto interpretativo complejo por parte del espectador." (Bruner, 1986/2004, p. 17). Como participantes de una cultura, el significado se vuelve público y compartido. Esta forma de vida adaptada culturalmente depende de conceptos compartidos y formas de discurso que utilizamos para negociar diferencias de significado e interpretación.

La cognición social considera las interacciones sociales para explicar la producción y recepción de narrativas. La forma de cognición enactiva que se propone para el entendimiento narrativo es la del hacer sentido en un modo participativo [participatory sense-making] (De Jaegher y Di Paolo, 2007). La narrativa es vista como una forma de proceso intersubjetivo de hacer sentido entre dos agentes (un narrador y un lector). Dar sentido a la literatura narrativa es concebido como un proceso interaccional de co-construcción de un mundo del cuento con un narrador (Popova, 2014). 
De acuerdo con este enfoque enactivo, interactuamos en el mundo humano a través de la acción práctica. La acción deliberada y auto-consciente nos permite perseguir un objetivo o meta específicos. Esta fenomenología de la agencia implica una intencionalidad que poseemos y que recíprocamente entendemos que los otros poseen. La agencia no es la habilidad simple de actuar en el mundo: son creencias, deseos e intenciones que tenemos y asumimos entonces que los demás tienen. Por lo tanto, las historias se entienden mejor como procesos de interacción modelada entre esencialmente dos participantes: un lector y un narrador. La interacción refiere a una forma participativa del lector -en oposición a una historia pre-dada que debe comprenderse-, entendiendo que los significados son construidos socialmente y no meramente recuperados.

Atribuimos una intención a una consciencia narrante y a la estructura de acción que integra la sucesión de eventos en una causalidad que se dirige hacia una meta: la meta del narrador. Cuando leemos narraciones escritas las estamos enactuando: las conferimos a un participante conversacional, una consciencia mediadora entre sí mismo y los eventos reportados. Popova dice que el narrador es "una instancia ficcional, aunque psicológicamente real, una instancia enunciatoria de un acto de contar" (Popova, 2015, p. 62). En ese sentido, considera entender a la narrativa como virtual: "es un proceso interaccional de co-construir un mundo de la historia con un narrador" (Popova, 2015, p. 9).

Lo que este trabajo se propone es indagar al performer mediante la obtención de sus descripciones de la experiencia. Consideramos estos músicos construyen sus propias concepciones de la performance, las cuales están informadas por la práctica. Esto abarca sus intenciones, reflexiones, pensamientos y sensaciones, que nos pueden permitir entender las acciones de los músicos. Para esto, abordaremos aspectos de la performance clásica en un contexto de relaciones sociales que el performer establece con diferentes personas. Se indagarán diferentes etapas: desde las primeras instancias de su estudio del instrumento hasta las instancias de presentación en público. De este modo, esperamos brindar información acerca de la perspectiva del performer que pueda ser considerada en relación a las concepciones tradicionales de la performance clásica (Sloboda y Toelle, 2018; Small, 1998).

Al tomar estas ideas como punto de partida nos propusimos indagar lo narrado en la performance, entendiendo que una narración depende del punto de vista, perspectiva o el conocimiento del mundo de un narrador (Bruner, 2002/2003). Por lo tanto, consideramos que para postular al performer como un narrador su perspectiva debe ser tenida en cuenta para ser investigada.

\section{Método}

Se diseñó un estudio de metodología cualitativa que consistió la realización de entrevistas a un grupo de músicos intérpretes, con el objetivo de obtener descripciones de la comunicación performer-público desde el punto de vista del performer. 


\section{Participantes}

Se seleccionó a un grupo de 11 músicos instrumentistas, integrado por 9 pianistas y 2 guitarristas $(7$ mujeres, 4 hombres; edad promedio $=54$ años; desviación estándar= 14.16) con experiencia en la realización de performance solista (promedio $=24$ años).

\section{Diseño y realización de las entrevistas}

Los instrumentos para la obtención de la información consistieron en entrevistas semi-estructuradas. El guion previo que permitió abordar los temas principales relativos a cada entrevista. Sin embargo, con el objetivo de mantener una conversación fluida, los temas fueron abordados de manera aleatoria de acuerdo a la interacción entrevistador-entrevistado propia de cada encuentro. Por lo tanto, las preguntas sirvieron como disparadores o catalizadores del flujo de la conversación, resultando en abordajes más o menos profundos de cada tema, según el caso. Los encuentros fueron planteados como una conversación entre músicos, estableciendo una relación intersubjetiva con el entrevistado de un modo no-intrusivo.

\section{Preparación de los datos y análisis de las entrevistas}

Las entrevistas fueron registradas en audio digital con un grabador de mano Zoom H4. Las transcripciones y análisis de los datos fueron realizadas con un software para el análisis de datos cualitativos (CAQDAS) Nvivo 11 (QSR International). El análisis de los datos estuvo inicialmente informado por el contexto conceptual de la investigación, y de algún modo determinado por algunas de las preguntas derivadas de dichos supuestos. En la primera fase, se realizó la codificación de pasajes de la entrevista en un proceso de intercambio entre la información obtenida y el conocimiento teórico previo. En etapas posteriores, dichas presuposiciones fueron cuestionadas, refinadas, o adaptadas hasta la confección y testeo de la guía analítica que se utilizó para la codificación de todas las entrevistas en la última fase (Schmidt, 2004). Finalmente, la información obtenida en la codificación fue organizada y preparada para su presentación mediante la selección de los pasajes en las palabras de los músicos. Estos pasajes fueron nuevamente abordados para profundizar en la explicación a la luz de los nodos y categorías obtenidos.

\section{Resultados}

Las descripciones de las entrevistas permiten entender aspectos la comunicación musical relativos a: (i) las personas o entidades con las que el performer interactúa en diferentes momentos de su actividad; (ii) la dirección o sentido de la interacción; (iii) la percepción del público que experiencia el performer; (iv) la intencionalidad/ expectativa en la comunicación; y (v) el contexto y la situación de la comunicación. 


\section{Interacciones y direcciones que caracterizan la comunicación}

Los músicos manifestaron establecer vínculos con otras personas, roles o entidades. Esto ocurre en diferentes momentos desde el primer contacto con la partitura, pasando por el ensayo y hasta la situación de performance en público. La actividad musical del performer puede entenderse como una construcción o co-construcción basada en modos de interacción social. En cuanto a las personas y roles intervinientes, la mayoría de éstos fueron indagados de manera directa en la formulación de las preguntas (por ejemplo, se les preguntó acerca del compositor y el público). En otros casos, las preguntas fueron indeterminadas o abiertas con el fin de indagar acerca de los vínculos sociales públicos o privados relativos a la práctica musical de los participantes. Así, los músicos se refirieron espontáneamente a interacciones con objetos o entidades no humanas, como la partitura y la obra. Teniendo en cuenta este tipo de personificaciones (Lakoff y Johnson, 1980/1986), las mismas se incorporaron la guía de codificación.

Con el propósito de brindar una presentación completa de los resultados, los datos de la codificación se organizaron en un cuadro que se presenta en la Tabla 1. Allí podemos distinguir, quién o qué establece una relación con el músico. La organización permite dar cuenta, por un lado, de las personas, objetos o entidades (compositor, público, obra, etc.); y, por el otro, cómo se vinculan las personas o entidades, en términos de la dirección descripta. Así, podemos profundizar acerca del cómo entendiendo que los performers se involucran en relaciones que se establecen en varias direcciones: (i) desde él/ella, (ii) hacia él/ella, (iii) consigo mismo o (iv) recíproca. En la Tabla 1 se presenta una selección de pasajes de las entrevistas que sirven de ejemplos para las direcciones identificadas en las relaciones que los músicos establecen. Los fragmentos 1.a y 1.b refieren a la relación desde el performer hacia el compositor. La primera (1.a) da cuenta de la comunicación con el compositor, entendida como una interacción virtual que real, sustentada en la intencionalidad del performer. La segunda (1.b) es expresada a través de relaciones espaciales: en principio, el performer y el compositor a cada lado del texto musical (partitura), y luego la acción dirigida en el espacio descripta como un acercamiento hacia la intencionalidad del otro.

La interacción que el performer establece, aunque pueda llegar a ser virtual, percibida o imaginada es entendida aquí como psicológicamente real. Esto puede ser descripto como una comunicación: surge al recibir el silencio del público e influencia las acciones que se realizan durante la performance (1.c). La interacción también surgir como un vínculo afectivo. La relación desde el compositor hacia el performer es nuevamente descripta en términos de espacio, y ocurre a partir de la llegada de la música del primero hacia el segundo (1.d). La relación del músico consigo mismo puede presentar dificultades para ser descripta. Los músicos pueden recurrir a una dirección circular en el espacio o retorno para describirla. Esto implica además una fenomenología de lo indivisible, cuando el músico es a la vez productor y receptor de la acción (1.e). Las relaciones recíprocas que el músico establece pueden ser descriptas en direcciones: como algo que va y que viene (1.f). La percepción también sirve a las descripciones, como cuando público y performer se escuchan mutuamente (1.g). 
Tabla 1.

Fragmentos de la conversación entre el investigador (I) y el performer (P) que dan cuenta de las direcciones en la interacción con personas o entidades

\begin{tabular}{lll}
\hline & Dirección & Relación con \\
\hline 1.a & Performer $\rightarrow$ & El compositor \\
1.b & Performer $\rightarrow$ & El compositor \\
& & \\
& & \\
$1 . c$ & Performer $\leftarrow$ & El público
\end{tabular}

\section{Fragmento de la conversación}

I - ¿Uno se comunica con el compositor? comp... Si el compositor se quiere comunicar con uno no sé, pero uno con el compositor sí. (Performer 7, pianista)

I - ¿Y tenés en cuenta intenciones del compositor? P - Sí, todo el tiempo.

I - ¿Y cómo las encontrás?

$\mathrm{P}$ - No sé, en los detalles uno intenta acercarse a la intencionalidad del otro, del que estuvo del otro lado, por eso te digo hay alguien que se esforzó mucho en poner lo que está escrito, como pudo. Cuando digo 'como pudo' es

porque el código es hasta ahí. (Performer 5, pianista)

I - ¿Qué sentís que recibís vos? P - Y, la atención, vos sentís que es una retroalimentación. Es como que trasciende el silencio, esa atención. Eso es como una comunicación porque eso a su vez hace que vos te involucres más, que te explayes o que te sueltes más. Vas sintiendo esa cosa. (Performer 2, pianista)

I - ¿Te parece que el compositor se comunica de alguna manera con el intérprete o con vos?

P - (silencio, piensa) Termina habiendo, supongo, algún tipo de comunicación. Hay a veces una cuestión como

de conexión, por lo menos sí, uno dice... yo agarro algo de Bach, a mí me gusta, y yo siento como que "uh, ¡qué groso esto!", me llega. Siento como que... como que uno se vincula afectivamente ¿no?, de alguna manera... como que llega, que le llega la música que el tipo compuso, te está llegando y uno como que se vincula. (Performer 11, guitarrista)

I - ¿Uno se puede comunicar consigo mismo? P - Sí, yo creo que sí. Porque el sonido te vuelve, vos lo producís, te vuelve. Es una maraña, sí. Te vas a escuch... si no te escuchás, ¿qué estás produciendo? Es... yo creo que hasta digamos ni siquiera hay una división, va y viene todo el tiempo. Circular, completamente. (Performer 7, pianista)

P - Cuando la gente va a escuchar... Entonces yo no me puedo dar el lujo de decir "hoy no le pongo nada". Por más que hay días que estoy mal o no me siento físicamente, me voy acomodando. Yo le debo respeto a la gente. Yo termino entrando en la música, es recíproco. Yo la produzco, pero la música me atrapa, viste. No sé cómo explicarlo. Una vez que entró a sonar te metés en el lenguaje. Sino no se podría hacer. (Performer 8, pianista)

I - ¿Pensás que hay comunicación entre vos y los demás? $P$ - Sí. Hay una comunicación, que va y que viene... pero esa obra que uno que está tocando el otro generalmente la conoce. Sabe qué va a pasar y lo está esperando. Y si no lo hacés, entonces le pasa algo. Hay algo que no te puedo traducir en palabras cómo es. No es una presunción, algo está pasando, es una certeza que uno tiene. Pero trasladarlo

a la palabra ¿cómo fue? No se puede decir. Yo tengo esa confianza que está yendo y viniendo. (Performer 2, pianista) 
Al profundizar en los verbos que describen relaciones, vemos dos que recrean situaciones de interacción verbal. Estas analogías pueden referir a situaciones de interrogación o diálogos que sirven para describir cómo el performer establece un vínculo con una persona o entidad, sea o no sea humana, en una situación real o virtual. En la Tabla 2 se presentan fragmentos que describen diálogos con la obra, la partitura, el compositor, el performer mismo, y el público.

En los dos primeros párrafos (2.a y 2.b) la relación se establece con entidades no humanas. En ambos casos lo descripto implica una relación dinámica (que evoluciona en el tiempo), como una maduración o actualización. Al decir que comprende o descubre la música a través de esta vinculación, consideramos que el performer construye el significado de la obra o partitura interactuando con un agente virtual. En el caso del compositor (2.c) el diálogo implica una relación con una persona que, aunque haya existido, el performer sólo puede conocer a partir de sus obras. Esta interacción virtual, imaginada o inferida, es posible debido a la intencionalidad del músico que puede o quiere interpretar en el texto intencionalidades atribuidas a una entidad humana. El diálogo consigo mismo (2.d) establece una comunicación cuando el performer adopta la perspectiva o posición de público. Aunque es descripto con enunciados verbales, el diálogo con el público (2.e) no implica su manifestación concreta, sino su percepción para interactuar mientras toca la obra.

El rol del performer es entendido tradicionalmente como el emisor o intermediario del mensaje del compositor. A través de las descripciones de los músicos entrevistados podemos encontrar evidencia de que puede adoptar diferentes perspectivas, como cuando se posiciona en el lugar de público: "Si yo toco para mí, yo soy el público. Siempre me estoy ubicando adentro tocando, y hay otro yo que está como afuera, siempre hay un público" (Performer 8, pianista). La capacidad de posicionarse desde el lugar de los otros parece ser una habilidad requerida para la actividad del performer; entonces, aunque esté solo tocando para sí mismo: "No experimento necesariamente que toco para mí. Siempre pienso, aunque esté solo en casa estudiando que estoy con otros, que esto es para alguien.” (Performer 4, pianista).

\section{Percibiendo al público}

En el modelo tradicional de la performance musical no se considera la participación activa del público. Esto, en principio, parece atentar contra una comunicación en ambos sentidos debido a que el músico sólo toca o transmite y el público sólo percibe o recibe. Preguntamos acerca de esto a los performers para obtener información:

I - ¿Y los mirás?

P - Cuando estoy tocando no, ni de casualidad. No puedo, porque estoy acá, el piano siempre está de perfil, nunca va a estar apuntando al público.

I - ¿Y escuchás?

P - No, trato de poner una barrera acá. Porque si no me distraigo y fui. (Performer 3, pianista). 
Tabla 1.

Fragmentos de la conversación entre el investigador (I) y el performer (P) que ejemplifican descripciones de diálogos en la interacción con personas o entidades

\begin{tabular}{|c|c|c|}
\hline & Diálogo con & Fragmento de la conversación \\
\hline 2.a & ...la obra & $\begin{array}{l}\text { P - El problema es cuando vos trabajás, analizás, convivís con la obra. } \\
\text { Esa convivencia para mí implica una relación dialógica con la obra. } \\
\text { En esa relación hay un proceso de maduración hasta que llegues a } \\
\text { comprender, a entender que los procesos de frase que vos querés hacer } \\
\text { tienen que ser de tal o cuál manera. (Performer } 4 \text {, pianista) }\end{array}$ \\
\hline 2.b & ...la partitura & $\begin{array}{r}\text { P - Lo primero que hago es decodificar. Así, ¡tac! A secas. Y después, } \\
\text { a medida que la vas tocando, como que es un diálogo contínuo con } \\
\text { la partitura. Como que vas descubriendo cosas, la música te devuelve } \\
\text { otras cosas, y así, qué sé yo. No sé. } \\
\text { I - ¿Y cómo sería ese diálogo? } \\
\text { P - Es como que todo el tiempo se va actualizando la música en vos. No } \\
\text { es lo mismo tocar una cosa después de un mes que el primer día que } \\
\text { la empezaste a tocar. Como que ya vas a niveles más macro, digamos, } \\
\text { de lo que suena. No estás tan pendiente de por ahí "ay, esta parte no } \\
\text { me sale" o "éste dedo". Como que ya fluye y bueno vos ya te vas como } \\
\text { preguntando otras cosas. (Performer 3, pianista) }\end{array}$ \\
\hline 2.c & ...el compositor & $\begin{array}{l}\text { P - Mirá, en una cuestión muy personal, yo a veces siento que dialogo } \\
\text { con Beethoven, cuando estoy tocando sus sonatas... No es ninguna } \\
\text { cosa misteriosa, simplemente... en el sentido de lo que me pasa con una } \\
\text { obra musical que veo un ser humano atrás, que compuso eso. Qué sé yo, } \\
\text { el } 15 \text { de mayo de } 1797 \text { Beethoven estaba en el compás } 15 \text { de la sonata } \\
\text { pastoral. El tipo está haciendo eso, ¿entendés? Es algún ser humano que } \\
\text { hace eso. (...) En ese sentido me parece comprender realmente qué es lo } \\
\text { que... (el entrevistado no lo completa y retoma) en éste diálogo con el } \\
\text { compositor. (Performer } 4 \text {, pianista) }\end{array}$ \\
\hline 2.d & $\begin{array}{r}\text {...el performer (sí } \\
\text { mismo) }\end{array}$ & $\begin{array}{r}\text { I - ¿Cómo sería tocar para uno mismo? } \\
\text { P - Te sentás a tocar para vos, porque te gusta, porque querés escuchar } \\
\text { eso, ésta obra que te gusta o la estudiaste. } \\
\text { I - ¿Hay una comunicación con uno mismo? } \\
\text { P - Sí. Podría haber un diálogo con uno mismo (pausa). } \\
\text { (Performer 2, pianista) }\end{array}$ \\
\hline 2.e & ...el público & $\begin{array}{r}\text { P - ...como que hay un diálogo. } \\
\text { I - ¿Existe una comunicación entonces? } \\
\text { P - Sí, el emisor emite, estoy tocando. Pero el receptor, por ejemplo, termina } \\
\text { algo, empieza otra cosa, la gente aplaude, por ahí empieza a hablar un } \\
\text { poquito... Yo de repente hago otra cosa de la que tenía pensada, empiezo } \\
\text { asíiii que se yo, bajito y hay como una especie de comunicación. Si yo te } \\
\text { estoy diciendo "callate la boca", ponele, bueno "arranqué, empecé a tocar" } \\
\text { entonces estoy diciendo algo, la gente se calla, me presta atención, todo el } \\
\text { público está así, y yo hago otra cosa, entonces es como un ida y vuelta en } \\
\text { ese sentido. Ahí hay una comunicación digamos, clara. Pero en ese mismo } \\
\text { nivel, con el resto de la música con la gente atenta. (Performer 6, pianista) }\end{array}$ \\
\hline
\end{tabular}

Aunque el modelo no permite el contacto directo con el público, esto no implica que el performer esté impedido de establecerlo. Es por esto que, en su lugar, hemos visto que depende de las intenciones del músico para generar un vínculo. Exceptuando a uno de los performers, todos los demás -y de diferentes maneras- dieron cuenta de una intención para percibir a sus espectadores. 
I - ¿Mirás al público?

P - Cuando puedo sí.

I - ¿y te influye?

P - Sí, porque ¿cómo me doy cuenta del feedback sino? Con los sonidos, pero no...

Es lindo mirar. (Performer 1, pianista).

Como veremos más adelante, este tipo de contacto incide de algún modo en la performance que los músicos realizan. A veces, no sólo requiere de mirar, sino de tener una percepción particular que resulta fundamental para el performer. En algunos casos, esto fue descripto en términos de escuchar al público:

I - ¿Cómo te das cuenta? ¿los ves?

P - No. Escuchás, percibís.

I - ¿Tenés tiempo para eso?

$\mathrm{P}$ - Si, cuando estás tocando tenés que sí. En un momento vos tenés que apropiarte de la atención del público. Porque vos lo que estás tocando en ese momento es lo más importante. Esa es la actitud, se lo merece el compositor (ríe). Sí. (Performer 7, pianista).

\section{I - ¿Qué diferencia encontrás?}

$\mathrm{P}$ - Yo puedo tocar solo en mi casa y emocionarme, pero cuando hay público... Cuando hay gente escuchándote, yo también estoy escuchando al público, lo tengo presente... aunque yo no los mire, yo sé que están ahí, sé que respiran... Hay una cosa que es... ya te digo, no la puedo describir, pero hay como un ida y vuelta... hoy en día se habla mucho de lo energético, yo.... No sé si es así. No lo sé, pero no es lo mismo tocar solo que con otro.... Porque yo también voy muchas veces a escuchar y yo desde el lugar que estoy de oyente, a mí me pasan cosas extraordinarias. Entonces lo traslado: "bueno al otro que me viene a escuchar le debe pasar lo mismo”. No soy solamente intérprete, también soy público. (Performer 8 , pianista).

Aquí también el performer se vale de su posición de público, siendo capaz de adoptar el punto de vista del receptor. Esto parece incidir en el modo en que la performance se construye:

I - ¿Sos de mirar?

P - No, pero lo sentís, lo sentís. Pero sentís, sobre todo la energía de los que están más cerca, aunque no estés mirando te das cuenta... Vos mirás así como global y ves si se mueve el cuerpo, si no se mueve el cuerpo... la actitud, eso también te transmite algo, y en el momento te empuja... lo mismo que el aplauso, lo que sea, pero generalmente yo soy bastante sensible al entorno en el momento de tocar, $y$ escucho si hay conexión, y escucho si hay silencio total cuando estoy haciendo la pausa, es como que sentís que estás conectado. Ahora si escuchás ruiditos, como 
que la gente está incómoda, ahí ya no es lo mismo, o si hay ruido de ambiente.

I - ¿Eso pensás que te cambia un poco? Digo, si forma parte...

P - Si, sí, yo creo que forma parte.

I - ¿De qué?

P - Forma parte de la interpretación de alguna manera ese intercambio en el momento, esa vinculación con el público, sí. (Performer 11, guitarrista).

\section{I - ¿Llegás a mirarlos?}

P - A veces sí, estoy tocando y veo las caras de la gente, depende con qué instrumento estoy tocando. Veo gente que por ahí me está mirando fijo, o me está mirando las manos. (...) No sé cómo sería, pero lo puedo sentir mientras toco. Porque van pasando cosas en el público que a mí también me hacen tocar ciertas cosas. (Performer 6, pianista).

\section{Intencionalidad y expectativa en la comunicación}

Durante la entrevista, la intencionalidad fue indagada en relación al compositor, a otros intérpretes, al público y a la propia intencionalidad del performer. Cuando se les preguntó, los performers fueron capaces de hablar sobre las expectativas del público en relación a lo que esperan presenciar cuando asisten a una performance. Debido a que no participa de manera activa, la intencionalidad del público no se infiere de manera directa. Considerando siempre el punto de vista del performer, decimos que éste tiene en cuenta las expectativas del público asociada a una intencionalidad. Esta interpretación se basa en la relación que vincula a la intencionalidad con la expectativa (Acero y Villanueva, 2012). En un sentido similar, la expectativa también es algo que el performer experiencia, con la diferencia que éste puede realizar acciones concretas que inciden en la comunicación de la obra, aun cuando pueda estar solo:

I - ¿Qué te parece que es lo más importante para interpretar una obra?

P - Lo más importante es tener la expectativa, que yo más que expectativa diría "duda". Qué duda hay antes de comenzar a ejecutar una obra para comunicarla. Porque si no ¿para qué va a ser? ¿no es cierto? Podría añadir teorías, que se yo. Te podrías estar comunicando con el autor, ¿no? A mí me suena medio extraño. Prefiero comunicarme con el público, aunque esté solo. Parece un contrasentido, pero esa es la expectativa: ¿qué comunicaré?, aunque sea a mí mismo. Por eso te digo, aunque esté solo, siempre hay "otra cosa" a quién comunicar, sino ¿para qué? (Performer 10, guitarrista).

El contexto y la situación de la comunicación. Los performers no realizan una performance independientemente del contexto en el que se lleva a cabo. Por el 
contrario, constituye uno de los factores más importantes que inciden al momento de presentarse ante el público:

\section{I - ¿Cómo es tocar para otros?}

P - Y, tengo que saber cómo son esos otros. Quienes van a ir, quién es el público que te va a ir a escuchar, que van a esperar. (...) Es una comunicación que se está estableciendo. Querés establecer una comunicación con toda esa masa. Tenés que pensar antes de hacerlo como para...

I - ¿Y si fuera una persona o dos?

P - Lo mismo. (Performer 1, pianista)

I - ¿Existe algo para comunicar?

P - Hay una música que se está tocando en particular. No estás tocando cualquier cosa, pero luego tampoco la estás tocando a cualquiera. Más que nada tiene que ver con esto que te decía que si uno logra que las cosas se hagan, que recuperen naturalidad, que se hagan vivas, lo que transmitís es eso. Es la obra hecha vida, eso es lo que tiene el hacerlo en vivo, que no tiene cuando no está el intérprete ahí en el escenario.

I - ¿A quién pertenece eso?

$\mathrm{P}$ - A una persona no. $\mathrm{O}$ a algo puntual no. Ese sí es el evento, que no es el acontecimiento, es el evento, es eventual. Es el que está sentado, son los que están sentados arriba, abajo del escenario. Es todo, por supuesto la música obviamente. (Performer 5, pianista)

El sentido de lo colectivo en la performance es determinante para entender el tipo de comunicación que es descripta por algunos performers. Incluso, el músico puede pensarse a sí mismo como un sujeto social en un contexto de amplio alcance del fenómeno musical. De esta manera se puede pensar a la performance como una actividad que permite todo tipo de interacción entre las personas:

I - ¿Para quién tocás?

P - Para la música. No es la música por la música, porque todo se sitúa en un contexto histórico, tratando de que la gente y uno se acerque a cosas más verdaderas, con una persona vinculada a lo individual y a lo colectivo. Desde ese punto de vista me parece que una presentación nunca debiera ser en una sola dirección, que la 
gente vaya a escuchar como yo toco, o que la gente vaya a disfrutar de como toco. Me parece que lo bueno está en la obra, en lo que a esa gente le pasa estando al lado de otras personas; y uno, aunque esté en el escenario está como en un círculo con todos los demás. Lo otro sería persistir en un individualismo que sería como clasista de alguna manera, y nunca inclusivo, viste. (Performer 8, pianista).

El contexto y la situación inciden en el performer y sus acciones, pero también pueden incidir en la auto-percepción del ser. Algunos músicos describen algún tipo de cambio en su rol o personalidad que puede ser pensado en su relación con los demás, y en sus intenciones de comunicarse con ellos:

I - ¿Cómo es tocar para los otros? ¿se hace algo diferente?

P - No.

I - ¿Entonces uno puede tocar para uno mismo y además para los otros?

P - Sí. Se hace solo. Sólo ver el público y ya no sos el mismo. Sí, me predispongo en esta determinación que te hablaba, pero no lo hago de otra manera. Cuando trabajo, trabajo pensando en que es para compartirlo. (Performer 5, pianista)

I - ¿Y seguís siendo el mismo?

P - Si, estoy como en estados distintos, ¿viste? Cuando estoy tocando puede ser parecido, como si fueren varios yo... Cuando era chico tocaba mucho para que me vieran. Ahora toco para que me escuchen. Que me escuchen pero que disfruten, no que me presten atención nada más.

Esto es así: lo que me interesa es la obra. Entonces yo disfruto la obra y el tipo disfruta la obra. Como consecuencia, si lo disfrutó le gusta lo que estoy haciendo. Pero básicamente es la obra lo que me interesa. (Performer 8, pianista).

Como habíamos visto anteriormente, esta comunicación puede ser percibida y descripta en el sentido de una reciprocidad en los estados de ánimo, lo afectivo y lo emocional, lo que produce una sensación de conexión con los demás:

I - ¿Sentís que recibís algo del público?

P - Sí, cuando recibís la atención, cuando se produce el silencio. Vos sabés que algo les está pasando parecido a lo que te pasa a vos. Cuando vos sentís que entregaste mucho entonces ahí hay mucha comunicación o comunión. (Performer 2, pianista) 
I - ¿Qué sería lo más importante para interpretar una obra?

P - Sentirla, yo creo que sentirla. Uno, una obra la toca cuando la siente en la yema, cuando vos sentís que tu yema es la que genera ese sonido. No es tan filosófico, es cuando vos sentís que realmente la yema del dedo está generando ese sonido. Porque hay todo un mecanismo, pero en el fondo... y que hay una conexión muy fuerte con el que escucha. Es una construcción colectiva de lo que vos le das y lo que recibe el otro. (Performer 7 , pianista).

A su vez, la comunicación con el público permite al performer tomar decisiones sobre la marcha acerca de las acciones que realiza o está por realizar. El contexto de la performance es el lugar y las personas que participan de ésta, pero también es dinámico cuando presenta situaciones nuevas, inesperadas o espontáneas:

I - ¿Para quién tocas?

P - Para mí. Pero cuando toco en público me debo al público. Cuando estoy en un escenario toco para la gente que escucha, independientemente del conocimiento musical que tenga.

En los conciertos los bises los tengo pensados de antemano, pero a veces no pegan en el momento y los cambio ahí mismo (Performer 9, pianista).

I - ¿Hay una sola manera de tocar una obra?

P - No. Para nada.

I - ¿Cómo hacés para encontrar tu manera?

P - Para mí es muy importante el evento en el que.... Yo estoy pensando en tocar la obra para otros, ¿no? El lugar, la espacialidad donde vos vas a trabajar, como influye en nuestro caso aparte el piano, cuál es la característica del evento, cómo está construido el programa, en qué lugar tocás, después de qué obra y antes de cuál, qué gesto vas a tener que generar si el público es muy disperso y vos tocas una obra con pianissimos, donde sino se sostiene el sonido no se dice nada, por ejemplo. Y depende de cómo uno esté también (Performer 7, pianista).

I - ¿Llegás a una versión ideal de tu interpretación? 
P - No. A veces pienso cosas así, pero después modifico constantemente las cosas. Porque siento que los lugares... como que la música, más allá del papel, es la gente que está alrededor, es el espacio. Es el escenario, es el piano en particular, entonces es como que... cambia. Y una misma obra a veces es muy diferente, no por mí sino por el receptor (Performer 6, pianista).

\section{Discusión}

La actividad del performer requiere producir la presentación de obras musicales frente al público, una actividad que se inserta en convenciones y validaciones sociales dentro de la práctica académica. Durante la preparación de la obra, la construcción del significado que el performer realiza es negociada y/o consensuada en relación a otros agentes sociales reales. Cuando estos no están disponibles, el performer puede convocarlos o evocarlos para ayudarse a entender la obra interactuando con un agente virtual. Por otro lado, el proceso de lectura y comprensión de la partitura implica establecer una interacción con ésta o con la obra: encuentros, diálogos, discusiones, convivencias, etc. Entendemos que son formas enactivas que recrean interacciones de la vida social. Esta construcción del sentido o el significado es realizada por el músico de manera activa al convocar a un interlocutor real o virtual que incluso puede constituirse en relación a sí mismo.

Por ejemplo, algunos músicos se refirieron a la situación de recrear la situación comunicacional adoptando el rol de oyente o público: de esta manera, el músico no estaría solo aun cuando está solo. En este sentido, el significado de la música no es determinado por una única persona, sino que requiere de un interlocutor válido para establecer un vínculo social y, en ese sentido, iniciar una búsqueda de significados posibles interactuando con la música.

Las descripciones obtenidas permiten pensar acerca de una interacción más cercana entre el músico intérprete y el público. Cada uno de los performers entrevistados representa un punto de vista particular, y el número de casos no nos permitiría generalizar acerca de los resultados obtenidos. Sin embargo, hemos visto que el performer puede percibir a las personas del público, aunque no los esté mirando o escuchando, sentir su conexión o compañía. Además, puede realizar atribuciones de intencionalidades en el público porque, a pesar de producir la música, en la performance también se involucra con ésta desde un lugar de receptor.

Así, las descripciones nos permiten entender que el músico se encuentra en una posición intermedia entre la composición de la obra y su performance. Por un lado, puede establecer una comunicación con el compositor, mientras que, por el otro, se comunica con el público. Hemos visto que el performer también dice comunicarse consigo mismo: es al mismo tiempo quien produce la música y quien la escucha. Es por esto que, desde la experiencia del performer, cuestionamos la direccionalidad 
del modelo de comunicación tradicional de una única vía y un único sentido. El modelo parece ser más complejo, es más una red de comunicaciones que pueden ocurrir de manera simultánea a través de la música. Para esto el performer se encuentra en un lugar privilegiado: su rol de mediador no implica transmitir un mensaje sin intervenir o interponerse; por el contrario, puede ser considerado como el centro de la comunicación. El performer experiencia la comunicación en diferentes direcciones, y esto es fundamental para entender a la performance como una práctica social donde se elabora el sentido.

Consideramos que en la interacción social la obra adquiere el significado compartido, de un modo análogo al que se establece entre un narrador y un narratario. Este vínculo consiste en: (i) situaciones interactivas de la vida social, (ii) instancias de comunicación y (iii) narraciones. Desde la perspectiva del performer podemos pensar que tanto su participación como la del público son necesarias para que la música adquiera un significado colectivo en un tiempo y lugar particulares. Este tipo de significado no se encuentra totalmente planteado de antemano en la partitura, estado final que el compositor ha establecido para la obra. El surgimiento de un nuevo estado de la obra que tanto el performer como el público co-construyen resulta un camino posible para pensar en narrativas que se producen en la performance.

\section{Referencias}

Abbate, C. (1991). Unsung voices: Opera and musical narrative in the nineteenth century. Princeton: Princeton University Press.

Acero, J. J. y Villanueva, N. (2012). Wittgenstein y la intencionalidad de lo mental. Análisis Filosófico, 32(2), 117-155.

Almén, B. (2008). A theory of musical narrative. Bloomington: Indiana University Press.

Brand, G., Sloboda, J., Saul, B. y Hathaway, M. (2012) The reciprocal relationship between jazzmusicians and audiences in live performances: A pilot qualitative study. Psychology of Music, 40(5), 634651. HTTPS://DOI.ORG/10.1177/0305735612448509

Bruner, J. S. (1986/2004). Realidad mental y mundos posibles: Los actos de la imaginación que dan sentido a la experiencia. (B. López, Trad.). Barcelona: Gedisa.

Bruner, J. S. (1990/1991). Actos de significado: Más allá de la revolución cognitiva. (J. C. Gómez Crespo y J. L. Linaza, Trads.). Madrid: Alianza.
Bruner, J. S. (2002/2003). La fábrica de historias: Derecho, literatura, vida. (L. P. López, Trad.). Buenos Aires: Fondo de Cultura Económica.

Cross, I. (2005). Music and meaning, ambiguity and evolution. En D. Miell, R. A. R. MacDonald, y D. J. Hargreaves (Eds.), Musical communication (pp. 27-43). Oxford: Oxford University Press on Demand.

Cross, I. (2010). La música en la cultura y la evolución. Epistemus. Revista de Estudios en Música, Cognición y Cultura, 1(1), 9-19. нттPs:// DOI.ORG/10.21932/EPISTEMUS.1.2700.0

Davidson, J. W. (1993). Visual perception of performance manner in the movements of solo musicians. Psychology of Music, 21(2), 103-113. HTTPS://DOI.ORG/10.1177/030573569302100201

De Jaegher, H. y Di Paolo, E. (2007). Participatory sense-making: An enactive approach to social cognition. Phenomenology and the Cognitive Sciences, 6(4), 485-507. HTTPS://DOI.ORG/10.1007/ s11097-007-9076-9 
DeNora, T. (2000). Music in everyday life. Cambridge: Cambridge University Press.

Español, S. (2010). Performances en la infancia: Cuando el habla parece música, danza y poesía. Epistemus. Revista de Estudios en Música, Cognición y Cultura, 1(1), 57-95. HTTPs://DOI. ORG/10.21932/EPISTEMUS.1.2702.0

Español, S. (Ed.). (2014). Psicología de la música y del desarrollo. Buenos Aires: Paidós.

Fludernik, M. (2009). An introduction to narratology. New York: Routledge.

Gabrielsson, A. y Juslin, P. N. (1996). Emotional expression in music performance: Between the performer's intention and the listener's experience. Psychology of Music, 24(1), 68-91. HTTPS://DOI.ORG/10.1177/0305735696241007

Geeves, A. M., McIlwain, D. J. y Sutton, J. (2014) Seeing yellow: 'Connection' and routine in professional musicians' experience of music performance. Psychology of Music, 44(2), 183-201. HTTPS://DOI.ORG/10.1177/0305735614560841

Gennete, G. (1983/1998). Nuevo discurso del relato. (M. Rodríguez Tapia, Trad.). Madrid: Cátedra.

Goehr, L. (1992). The imaginary museum of musical works: An essay in the philosophy of music. Oxford: Clarendon Press.

Hevner, K. (1936). Experimental studies of the elements of expression in music. The American Journal of Psychology, 48(2), 246-268. нтTPs:// DOI.ORG/10.2307/1415746

Holmes, P. A. (2011). An exploration of musical communication through expressive use of timbre: The performer's perspective. Psychology of Music, 40(3), 301-323. HTTPS://DOI. ORG/10.1177/0305735610388898

Imberty, M. (1997). Peut-on parler sérieusement de narrativité en musique? En A. Gabrielson (Ed.), Proceedings of the 3rd Triennial Conference of European Society for the Cognitive Sciences of Music (ESCOM1997) (pp. 23-32). Uppsala: ESCOM.

Juslin, P. N. (2005). From mimesis to catharsis Expression, perception and induction of emotion in music. En D. Miell, R. A. R. MacDonald, y D. J. Hargreaves (Eds.), Musical communication (pp. 85-115). Oxford: Oxford University Press.

Klein, M. L. (2013). Musical story. En M. L. Klein y N. Reyland (Eds.), Music and narrative since 1900 (pp. 3-28). Bloomington: Indiana University Press.

Lakoff, G. y Johnson, M. (1980/1986). Metáforas de la vida cotidiana. (C. G. Marín, Trad.). Madrid: Cátedra.
Malloch, S. (1999). Mothers and infants and communicative musicality. Musice Scientio, 3(1), 29-57. HTTPS://DOI. ORG/10.1177/10298649000030\$104

Malloch, S. y Trevarthen, C. (Eds.). (2009). Communicative musicality: Exploring the basis of human companionship. Oxford: Oxford University Press.

Martínez, I. C. (2007). La composicionalidad de la performance adulta en la parentalidad intuitiva. En P. Jacquier y A. Pereira Ghiena (Eds.), Actas de la VI Reunión de SACCoM, "Música y Bienestar Humano» (pp. 25-34). Buenos Aires: SACCoM Sociedad Argentina para las Ciencias Cognitivas de la Música.

Maus, F E. (1988). Music as drama. Music Theory Spectrum, 10(1), 56-73. HTTPs://DOI.ORG/10.1525/ MTS.1988.10.1.02A00050

Maus, F. E. (1991). Music as narrative. Indiana Theory Review, 12, 1-34.

Maus, F. E. (2005). Classical instrumental music and narrative. En J. Phelan y P. J. Rabinowitz (Eds.), A companion to narrative theory (pp. 466-483). Oxford: Blackwell Publishing.

Meelberg, V. (2006). New sounds, new stories: Narrativity in contemporary music. Leiden: Leiden University Press.

Miell, D., MacDonald, R. A. y Hargreaves, D. J. (Eds.). (2005). Musical communication. Oxford: Oxford University Press.

Nattiez, J.-J. (1990). Can one speak of narrativity in music? Journal of the Royal Musical Association, 115(2), 240-257.

Nattiez, J.-J. (2013). The narrativization of music. Music: Narrative or proto-narrative? Human \& Social Studies. Research and Practice, 2(2), 61-86. HTTPS://DOI.ORG/10.2478/HSSR-2013-0004

Popova, Y. B. (2014). Narrativity and enaction: The social nature of literary narrative understanding. Frontiers in Psychology, 5. HTTPS://DOI. ORG/10.3389/FPSYG.2014.00895

Popova, Y. B. (2015). Stories, meaning, and experience: Narrativity and enaction. New York/ Abingdon: Routledge.

Rink, J. (1994). Chopin's ballades and the dialectic: Analysis in historical perspective. Music Analysis, 13(1), 99-115. HTTPS://DOI.ORG/10.2307/854282

Rink, J. (1999). Translating musical meaning: The nineteenth-century performer as narrator. En N. Cook y M. Everist (Eds.), Rethinking music (pp. 217-238). Oxford: Oxford University Press. 
Scherer, K. R. y Oshinsky, J. S. (1977). Cue utilization in emotion attribution from auditory stimuli. Motivation and Emotion, 1(4), 331-346. HTTPs:// DOI.ORG/10.1007/BF00992539

Schmidt, C. (2004). The analysis of semi-structured interviews. En U. Flick, E. von Kardoff, y I. Steinke (Eds.), A companion to qualitative research (pp. 253-258). Londres: Sage.

Shannon, C. E. y Weaver, W. (1949). The mathematica theory of communication. Illinois: Urbana.

Shifres, F. (2007). Beyond cognitivism. Alternative perspectives on the communication of musical structure through performance (tesis doctoral inédita). University of Roehampton, Londres.

Sloboda, J. A. y Toelle, J. (2018). The audience as performer: Examining the effect of new music written for audience participation. En R. Parncutt y S. Sattmann (Eds.), Proceedings of the 15th International Conference on Music Perception and Cognition (ICMPC) and the 10th Triennial Conference of the European Society for the Cognitive Sciences of Music (ESCOM) (p. 329). La Plata/Motreal/Syndey/Graz: Centre for Systematic Musicology.
Small, C. (1998). Musicking: The meanings of performing and listening. Hanover/Londres: Wesleyan University Press.

Talbot, M. (2000). The work-concept and composercentredness. En M. Talbot (Ed.), The musical work: reality or invention? (pp. 168-186). Liverpool: Liverpool University Press.

Terasti, E. (1994). A theory of musical semiotics. Bloomington/Indianapolis: Indiana University Press.

Van Zijl, A. G. W. y Sloboda, J. (2011). Performers' experienced emotions in the construction of expressive musical performance: An exploratory investigation. Psychology of Music, 39(2), 196-219. HTTPS://DOI.ORG/10.1177/0305735610373563 